\title{
Echo Questions, Echo Negation, and Split CP*
}

\author{
Nicholas Sobin \\ The University of Texas at El Paso \\ njsobin@utep.edu
}

\begin{abstract}
This work examines English echo questions (EQs) against the background of Rizzi's (1997) analysis of split CP. It argues that EQs do not behave as the split $\mathrm{CP}$ analysis predicts that they should, and that their behavior can instead be straightforwardly explained within the classic CP analysis. Further, what are termed here 'echo negations' of negative inversion constructions are shown not to parallel EQs, a surprising result if negative inversion architecture parallels question architecture, as claimed by split CP proponents. In general, classic CP architecture is more appropriate for analysing this range of phenomena.
\end{abstract}

Rizzi (1997) presents what has been termed a split analysis of Complementizer Phrase (CP). This is sketched in (1) below. The proposal is very broad, and it is claimed to explain a variety of facts about the English complementizer system. In this paper, I will not take on many of the large aspects of the proposal. Here, I wish to deal with two phenomena each of which raises some degree of doubt about the extent to which a split $\mathrm{CP}$ analysis is explanatory of the CP architecture of English. This in turn raises questions about the universality and perhaps the efficacy of split $\mathrm{CP}$. The central facts to be discussed here concern echo questions (EQs) and their correspondence to $\mathrm{CP}$ structure under various assumptions about what $\mathrm{CP}$ structure is like. As I will try to show, a description of the patterning of possible and impossible EQs in English appears to be fairly straightforward under what I will call the 'classic' CP analysis. In contrast, the description of EQs becomes more complicated under the split $\mathrm{CP}$ analysis. Following this is a brief consideration of negative inversion (NI) constructions and a phenomenon that I will term 'echo negation'. If NI constructions parallel questions in their involvement with CP structure, as has been claimed, then one might expect their 'echo negation' forms to have properties similar to EQs; however, as we will see, they do not. Thus, these findings constitute a small bit of evidence that the classic analysis of CP, one consisting of Spec, $\mathrm{CP}$ and $\mathrm{C}$, may be more appropriate for English. 


\section{A Sketch of the Split CP}

Rizzi's now well-known elaborated analysis of the CP shell (1997) is shown in (1):

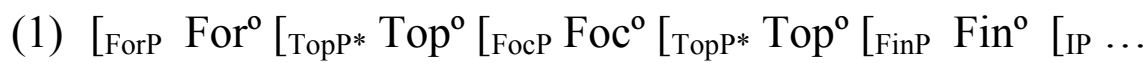

To quickly review the major features which are relevant to this discussion, the $\mathrm{CP}$ shell is divided into what Rizzi designates as a high 'Force' layer, and a low 'Finiteness' layer. Sandwiched in between these layers are possible topic and focus positions. ${ }^{1}$ Both adverb movement and topicalization are initially analyzed as involving the same positioning, movement to/placement in Spec, TopP (Rizzi 1997: 300). Thus, topicalization of an argument and fronting of an adverbial result in roughly parallel structures, as in (2):

(2) a. [ForP ... [TopP your article Top $^{o} \ldots$ [IP she really enjoyed $\left.\left.t_{i}\right]\right]$

b. [ForP ... [TopP tomorrow Top ${ }^{0}$... [IP she will read it]]]

The declarative complementizer that is high, in Force ${ }^{0}$ (Rizzi 1997: 301, 312), as in (3a). However, its non-phonetic counterpart (intuitively null that), is a null finite head in Fin ${ }^{\circ}$ (Rizzi 1997: 312), which is low in the structure, as in $(3 b)$ :

(3) a. ...said [ForP that [Topp yesterday $\operatorname{Top}^{\mathrm{o}} \ldots$ [IP she really enjoyed your article]]]

b. ...said ... [FinP [ $\left.\mathrm{Fin}^{\circ} \varnothing\right]$ [IP she really enjoyed your article]]]]

The infinitival complementizer for is also low, in Fin ${ }^{\circ}$ (Rizzi 1997: 301), as in (4):

(4) ... wanted very much ... [FinP [Fin ${ }^{\circ}$ for] [IP her to enjoy your article]]]]

\footnotetext{
*An earlier version of this paper was read at the spring meeting of the LAGB, University of Leeds. I am grateful to the audiences of both presentations for their insightful and helpful comments, and especially to Bob Borsley and Fritz Newmeyer for their helpful input. Any errors are my own.

${ }^{1}$ Rizzi argues that the non-recursive character of FocP can be explained by the observation that [Spec, FocP] is 'new' information, and the complement of $\mathrm{Foc}^{\circ}$ is 'given' information. Hence, this complement cannot be another FocP, something containing 'new' information (in Spec). Assuming that this is correct, then a Topic/Focus distinction may not be needed in the general architectural scheme. Instead, we may have the simpler available structure in (i), with T/FP simply being undifferentiated in the abstract as to what content it might have:

(i) $\left[\right.$ ForP For $^{\mathrm{o}}\left[\mathrm{TFP}^{*} \mathrm{~T} / \mathrm{F}^{\mathrm{o}}\left[\mathrm{FinP}_{\mathrm{P}}\right.\right.$ Fin $^{\mathrm{o}}[\mathrm{IP} \ldots$

That is, these are only available structural positions, with no preliminary semantic bias. However, a complication with this possible simplified view is the claim that the question operator seeks out [Spec, FocP], which doesn't exist per se in (i). Perhaps the noncooccurrence of FocP with question operators is, like the non-occurrence of FocP recursion, semantically based.
} 
Question operators in main clauses are claimed to occupy an intermediate position, namely, Spec, FocP (Rizzi 1997: 298-300), as in (5a). Question operators in embedded clauses are claimed to land higher. They occupy Spec, ForceP, as in (5b).

(5) a. [ForP [FocP What ${ }_{i}\left[\right.$ Foc $^{\circ}$ might $\left._{j}\right]\left[\right.$ FinP $\left[\right.$ IP she $t_{j}$ see $\left.\left.\left.\left.t_{i}\right]\right]\right]\right]$

b. ...wonders [ForceP what Force $^{\mathrm{o}}{ }_{\text {FocP }}$ Foc $^{\mathrm{o}}{ }_{\text {FinP }}$ Fin $^{\mathrm{o}}{ }_{\text {IIP }}$ she might see $t_{i}$ ]]]]]

Thus, both classic CP elements and topic and focus elements appear sprinkled throughout the now complex CP system. Surprisingly, despite this 'spreading' of CP elements and claims of extended distinctions, this complex layer is also claimed to 'collapse'. In particular, unless a topic or focus element appears within this layer, forcing apart Force and Finiteness, these two heads/layers combine into a single-headed layer, with a single head carrying features of both force and finiteness (Rizzi 1997: 312-315). This is roughly represented in (6), with that in (6a) (following Rizzi's verbal characterization) encoding 'primarily' force, and the null finite head in (6b) encoding 'primarily' finiteness:

(6) a. ...said [For/(Fin)P that [IP she really enjoyed your article]]

b. ...said [(For)/FinP $\varnothing[$ [IP she really enjoyed your article]]

This brief sketch will suffice for present purposes. Let us turn next to EQs in English.

\section{Echo Questions}

First, I will offer a sketch of EQ facts in classic CP terms, for the reason that certain possible generalizations about them become readily apparent on this analysis. Later, I will consider a split CP analysis.

\subsection{EQs and Classic CP Elements}

EQs may be analyzed (following Sobin 1978, 1990) as falling into two general types. One type, a pseudo-EQ, involves posing a normal question such as (7b) to a declarative utterance such as (7a).

(7) a. U: [CP -WH [IP Mary dated Beethoven]

b. E: [CP Who did [IP Mary date ]] $\uparrow$ ? (a pseudo-EQ)

Such an EQ has final rising ('echo' or 'surprise') intonation (noted here by ' $\uparrow$ ', a feature I will simply assume in all further representations). 
The second type of EQ, a syntactic EQ, (as in (7c) below) involves four key features, as listed in (8). (These are based on Sobin 1990: 146, but with some characteristics revised to conform to more current assumptions following Chomsky 1995; see also Dumitrescu 1990, 1991):

(8) Properties of syntactic EQs in 'classic' CP terms:

a) surprise intonation $(\uparrow)$;

b) 'COMP freezing' - an exact copy of the $\mathrm{LF}$ (/post-spellout) $\mathrm{CP}$ structure of the utterance being echoed;

c) 'B-binding' - unselective (C. L. Baker-style) binding in LF of EQintroduced (D-linked and in-situ) wh-phrases (Pesetsky 1987);

d) a 'copy', possibly loose, of the non-CP elements of the utterance being echoed.

Thus, to the utterance (7a) above, we may also have an EQ response like (7c), a true syntactic EQ. The structure $\left(7 c^{\prime}\right)$ illustrates the property noted in (8b) of Comp-freezing:
a. U: [CP -WH [IP Mary dated Beethoven]]
c. E: Mary dated who $\uparrow$ ? (a syntactic EQ)
$\mathrm{c}^{\prime}$. [ [CP -WH [IP Mary dated who]]

The CP layer of (7a) contains only a simple -WH complementizer, and it is this simple CP configuration that is frozen or echoed in $\left(7 \mathrm{c} / \mathrm{c}^{\prime}\right)$. I will say more later about binding the in-situ interrogative $w h o$ in $\left(7 \mathrm{c} / \mathrm{c}^{\prime}\right)$.

If the utterance being echoed is non-declarative, e.g., a simple yes-no question, then a pseudo-EQ is not possible. Pseudo-EQs may only be formed in response to a declarative utterance. Also not possible is any syntactic EQ which does not match the ('classic') Comp structure of the utterance, as illustrated in (9):

(9) a. U: [CP [C Did] [IP Mary meet Mozart at the party]]? $[+\mathrm{WH}]$

b. *E: [CP Who did [IP Mary meet at the party]]? $[+\mathrm{WH}]$

c. *E: [CP -WH [IP Mary met who at the party]]?

d. E: [CP [C Did] [IP Mary meet who at the party]]? $[+\mathrm{WH}]$

Question (9b) fails as a possible pseudo-EQ to (9a) since (9a) is not declarative. Again, only a declarative U can trigger a pseudo-EQ. (9b) and (9c) each fail as syntactic EQs to (9a) because neither matches the Comp 
structure of (9a), a simple interrogative C filled with did and an empty Spec,CP. Only (9d) succeeds as a syntactic EQ here, since it alone matches the Comp structure of (9a). This is a somewhat striking finding in that in non-EQ syntax, a question with such a $w h$-phrase would be ungrammatical unless that wh-phrase had moved to Spec, CP as in (9b).

The Comp-freezing aspect of syntactic EQ formation displays another dramatic result. Out of context, a construction such as (10a) is normally considered impossible (a Superiority violation), and (10b) is deemed the only derivable sequencing of the elements involved: ${ }^{2}$

(10) a. *What did who eat at the party?

b. Who ate what at the party?

However, there are utterances to which a construction such as (10a) is the only viable EQ response, and one like (10b) is not possible. So, consider (11a):

(11) a. U: [CP What did [IP Jack the Ripper eat at the party]]?

b. $\mathrm{E}:[\mathrm{CP}$ What did [IP who eat at the party]]? (=10a)

c. *E: [CP Who [IP ate what at the party]]? (=10b)

Here, the acceptability judgments of EQ responses to (11a) are the reverse of those in (10), a fact explained neatly by Comp-freezing.

Syntactic EQs also involve unselective binding or B-binding, as noted in (8c). Thus, in addition to the CP layer being frozen on the elements of the utterance being echoed, a B-binder is introduced which binds any EQintroduced in-situ wh-phrase. (12) shows fuller representations of the earlier EQ structures in $\left(7 c^{\prime}\right),(9 d)$, and (11b) which here include a B-binder Q:

(12) a. E: [CP $\mathrm{Q}_{\mathrm{i}}\left[\mathrm{CP}-\mathrm{WH}\left[{ }_{\mathrm{IP}}\right.\right.$ Mary dated who $\left.\left.\left.\mathrm{i}\right]\right]\right]\left(=7 \mathrm{c}^{\prime}\right)$

b. E: ${ }_{\mathrm{CP}} \mathrm{Q}_{\mathrm{i}}\left[{ }_{\mathrm{CP}}\right.$ Did [IP Mary meet $\mathrm{who}_{\mathrm{i}}$ at the party]]]? (=9d)

c. $\mathrm{E}:{ }_{\mathrm{CP}} \mathrm{Q}_{\mathrm{j}}\left[\mathrm{CP}_{\mathrm{CP}} \mathrm{What}_{\mathrm{i}} \mathrm{did}\left[\mathrm{IP}_{\mathrm{Pho}}\right.\right.$ eat at the party $\left.\left.\left.\mathrm{t}_{\mathrm{i}}\right]\right]\right]$ ? $(=11 \mathrm{~b})$

As is typical of syntactic EQs, the interrogative elements in the now frozen CP layer lose their interrogative force. In effect, it is as if the clause containing them had become subordinated (in the sense that wh-phrases in subordinate/embedded clauses such as I asked who Mary saw do not seek a response). Only the now higher B-binder and the co-indexed in-situ wh-phrase which it binds have interrogative force. Consequently, although an original utterance such as (11a) would have sought a response like (13a), its EQ (12c)

\footnotetext{
${ }^{2}$ Originally analyzed as violations of the Superiority Condition (Chomsky 1977), sentences such as (4a) have since received a variety of other explanations in more recent works, e.g., the Minimal Link Condition (Chomsky 1995). For present purposes, it will suffice simply to note their ungrammaticality as normal questions.
} 
does not allow (13a), but instead requires something like (13b), a response only to the EQ-introduced wh-phrase:

(11) a. U: [CP What did [IP Jack the Ripper eat at the party]]?

(12) c. $E:\left[{ }_{C P} Q_{j}\left[C P\right.\right.$ What ${ }_{i} \operatorname{did}\left[{ }_{I P}\right.$ who $_{j}$ eat at the party $\left.\left.t_{i}\right]\right]$ ? (=11b)

(13) a. *R: Peanuts!

b. R: Jack the Ripper!

\subsection{EQs and Non-CP Elements}

In contrast to classic $\mathrm{CP}$ elements, non- $\mathrm{CP}$ elements appear not to be frozen in position. Consider, for example, the sentences in (14):

(14) a. U: Bill said that Mary was kissed by Mozart.

b. E: Bill said that Mary was kissed by who?

c. E: Bill said that who kissed Mary?

d. U: Bill wondered if an oyster kissed Mary.

e. E: Bill wondered if what kissed Mary?

f. E: Bill wondered if Mary was kissed by what?

Here, the EQ is freely either active or passive. In either case, the EQintroduced wh-phrase is not a part of the frozen CP layer. The presence of both that/if and who/what in (14c) and (14e) are indications of this.

On the other hand, in (15a), where the interrogative argument who is CPlocated in the $U$, it is frozen in place in its passive EQ (15b), and the active form $(15 \mathrm{c})$ is not possible:

(15) a. U: Bill wondered who was kissed by an oyster

b. E: Bill wondered who was kissed by what?

c. *E: Bill wondered what kissed who(m)?

To summarize here, under the classic analysis of $\mathrm{CP}$, we can straightforwardly characterize key restrictions on possible EQs relative to the $\mathrm{CP}$ structure of the utterance. In a nutshell, the CP of the EQ is simply a frozen copy of the utterance $\mathrm{CP}$, as characterized in (8b), with B-binding as in (8c). It is worth noting here that there is not a 'special' EQ syntax. This is a 'normative' analysis which employs devices available to other normal syntactic constructions, such as B-binding, which Pesetsky (1987) argues is employed in connection with $\mathrm{D}$ (iscourse)-linked wh-phrases which appear to violate Superiority, as in Which movie did which person see? It is only Compfreezing, a discourse strategy interacting with the hard syntax, which is unusual or peculiar to EQs. 
Now, with this brief sketch of EQ formation in classic CP terms, let us turn to the question of how EQs appear to operate in the context of the split CP proposal.

\section{EQs and Split CP}

Here, we pose the following question: How neatly does the split CP hypothesis allow limitations on EQ formation to be described or explained?

First, consider an intuitive notion Force and the sentences in (16)-(17), where the verb know allows either a declarative or an interrogative complement:

(16) a. U: Bill knows that Mary kissed Mozart

b. E: Bill knows that Mary kissed who?

c. *E: Bill knows whether Mary kissed who?

(17) a. U: Bill knows whether Mary kissed Mozart.

b. E: Bill knows whether Mary kissed who?

c. *E: Bill knows that Mary kissed who?

If we follow Rizzi's initial characterization of Force simply as the designation of whether a clause is interrogative, declarative, etc. (Rizzi 1997: 283; 301), then we might conclude from the patterning in (16) and (17) that Force is frozen. However, if we consider split CP in greater detail, the picture becomes less clear.

As noted earlier, in a split $\mathrm{CP}$, the phonetic declarative complementizer that appears in Force ${ }^{\mathrm{o}}$ but the non-phonetic finite head ('null' that) is in Fin'. Now, in English, if the choice of the overt declarative complementizer that is 'optional' in a given utterance, then it is also optional in its EQ, as the sentences (18a) and (18e) illustrate: 
(18) a. U: Bill knew (that) Mary liked cigars.

b. ...knew [CP (that)[IP Mary liked cigars $[-\mathrm{WH}]$

c. ...knew [ForP $\left[\right.$ For $^{\circ}$ that $]\left[\mathrm{FinP}\left[\mathrm{Fin}^{\circ} \varnothing\right][\right.$ IP Mary liked cigars ...

d. ...knew [FinP [ Fin $\left.^{\circ} \varnothing\right]$ [IP Mary liked cigars ]]

e. E: Bill knew (that) Mary liked what?

f. ...knew [CP (that)[ip Mary liked what ]] $[-\mathrm{WH}]$

g. ...knew [ForP $\left[\mathrm{For}^{\circ}\right.$ that $]\left[\mathrm{FinP}\left[\mathrm{Fin}^{\circ} \varnothing\right][\right.$ IP Mary liked what $\left.]\right]$

h. ...knew [ $\operatorname{FinP}\left[\mathrm{Fin}^{\circ} \varnothing\right][$ IP Mary liked what $\left.]\right]$

In (18), that may or may not appear in the utterance, and it also may or may not appear in the corresponding EQ, whether or not it has appeared in the utterance. Under the classic analysis of $\mathrm{CP}$, this fact is easily accommodated: in (18b) and (18f), the declarative complementizer is frozen in its simple declarative or -WH aspect, though its phonetic form is still optional in either $U$ or EQ.

In the split $\mathrm{CP}$ analysis, however, there is not the same neat structural correspondence between utterance and EQ CP structure. Consider first the case where the special collapse of Force and Finiteness mentioned earlier does not take place. (I mention this possibility because there are reasons to doubt that it should.) $)^{3}$ Then sentence (18a) has either the structure (18c) with overt

\footnotetext{
${ }^{3}$ Ideally, this theory eliminates ' $\mathrm{C}$ ' as a category. A major reason that the that/øFin crunch has plausibility may be that these two items are still being thought of tacitly as Cs, and therefore as intrinsically related. However, since they are not Cs in this theory (and in fact nothing is), and since they have no special intrinsic relationship to each other (beyond the relationship imposed on them by Rizzi), the crunch really is an oddity relative to the elements (distinct heads) which are involved. Also, this isn't claimed to be a case of the major process which combine heads, namely, head movement.

Second, this is a theory that basically says that (what was) CP is thick with structure, not thin. It is an 'expansionist' theory. So the 'crunch' is simply unexpected on any general grounds within the theory. It looks like a simple case of really needing what we had before, and combining it with a later analysis.

Third, the crunch is posited in an attempt to account for the C-t effect and the adverb effect. Split CP per se (as Rizzi recognizes) loses any prediction with respect to the base C-t effect, so the crunch is posited to allow the Rizzi 1990 account to kick in, a theory which relies on 'classic' CP structure. The 'crunch' is a way of getting it back when needed.

Fourth, a part of the motivation for split CP is to explain the claimed fact that that is required before an adverb-effect-inducing adverbial. However, a key part of the analysis is the claim that there is no null force head, so this prediction rests in part on an ad hoc claim about the lexicon. And even this claim appears hard to maintain since it is necessary to posit a null Fin head which counts as a Force head. Further, it isn't clear that lack of a
} 
that or (18d) with only a finite null head, and the parallel analyses hold for the EQ, with (18g) showing overt that and (18h) showing the null finite head. The problem is that (18c) might be echoed by (18h), and (18d) by (18g). So in this non-collapse scenario, it might be claimed that Finiteness is frozen, though oddly, Force is not. This is the reverse of the intuitions about (16)-(17), not a very intuitive result.

Next consider the case where the collapse of Force and Finiteness in sentences like (18) does take place. (Rizzi claims that they 'fuse' or unify when no topic or focus element (including a moved adverbial) is present, as was illustrated in (6) (repeated here).

(6) a. ...said [For/(Fin)P that [IP she really enjoyed your article ]]

b. ...said [(For)/FinP $\varnothing[$ [IP she really enjoyed your article ]]

In this case, utterance (18a) with or without that will have as its structure either (18i) or (18j), respectively, and the EQ with or without that will have either (18k) or (181).

(18) i. U: Bill knew [For/(Fin)P [For/(Fin) that] [IP Mary liked cigars]]

j. U: Bill knew [(For)/FinP [(For)/Fin ${ }^{\circ}$ Ø] [IP Mary likes cigars]]

k. E: Bill knew [For/(Fin)P [For/(Fin) ${ }^{\circ}$ that] [IP Mary liked what]]?

1. E: Bill knew [(For)/FinP [(For)/Fin $\left.{ }^{\circ} \varnothing\right]$ [IP Mary liked what $]$ ?

Again, (18k) may echo (18j), and (181) may echo (18i). Though the structures look somewhat closer, given the claimed differences in feature composition and the problem of the categorial indentity of this head (and of the projected phrase) (Rizzi 1997: 312), even this looks somewhat 'fuzzy' as a proposed case of Comp freezing or copying. And this is as good as it gets.

The structural correspondence of uttered and echoed CPs degrades further in structures where a topic is involved. As already noted, an adverbial in Spec,TopP forces apart the Force and Finiteness layers, with Force obligatorily showing that. Assuming this, consider the possible utterance and echo pairs of (19) and (20):

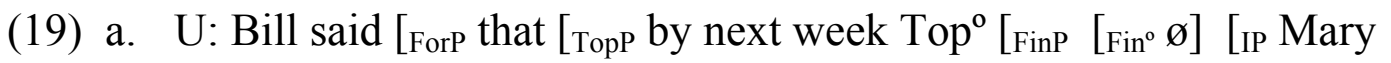
will be smoking cigars ...

b. E: Bill said [(Force)/FinP $\left[{\text { (Force }) / F_{i n}^{\circ}} \varnothing\right]$ [IP Mary will be smoking what by next week...?

(20) a. U: Bill said [(Force)/FinP $\left[{ }_{\left(\text {Force }_{\text {Fin }}{ }^{\circ}\right.} \varnothing\right]$ [IP Mary will be smoking cigars by next week ...

complementizer with the adverbial actually results in strong unacceptability (Sobin 2002: 544). 
b. E: Bill said [ForP that $\left[{ }_{\text {TopP }}\right.$ by next week $\operatorname{Top}^{\circ}{ }_{\text {FinP }}\left[\mathrm{Fin}^{\circ} \varnothing\right]$ [IP Mary will be smoking what ...?

These are not the only possible U-EQ pairs, but they are possible ones. Under this analysis of CP, the utterance and EQ pairs in (19) and (20) have quite different CP architectures, with little in the way of obvious structural correspondence between them. There appears to be no simple or direct statement available for capturing or delimiting the echo possibilities.

By contrast, the classic analysis of $\mathrm{CP}$ together with the rule of Compfreezing predicts the possibilities in (19) and (20). Assume, as Lasnik \& Saito (1992) (and others) have claimed, that expressions like by next week are IP(or AgrP-) adjuncts. Then the utterance-echo correspondences in (19) and (20) may have the structures shown in (21) and (22).

(21) a. U: [CP $\varnothing$ Bill said [CP that [IP by next week [IP Mary will be [-WH] $[-\mathrm{WH}]$ smoking cigars]]]]

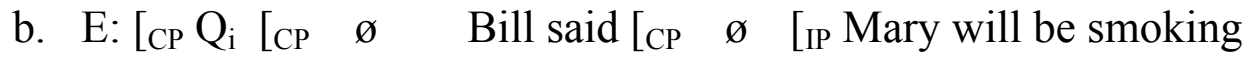
$[-\mathrm{WH}]$ what ${ }_{\mathrm{i}}$ by next week]]]? $[-\mathrm{WH}]$
a. U: [CP $\varnothing \quad$ Bill said [CP $\varnothing \quad$ [IP Mary will be smoking $[-\mathrm{WH}]$ $[-\mathrm{WH}]$ cigars by next week]]]

b. E: [CP Qi [CP $\varnothing$ Bill said [CP that [IP by next week [IP Mary $[-\mathrm{WH}]$ will be smoking whati]]]]?

Here, as was the case in (18b) and (18f), it is CP containing a simple [-WH] complementizer which is frozen. The phonetic character of the complementizer is not at issue, as noted earlier. The adverbial phrase is mobile because in this analysis it is not a part of CP structure.

The split CP architecture encounters further complications with EQs given what it indicates about the elements that may occupy the Focus layer. $\mathrm{Spec}, \mathrm{FocP}$ is the proposed landing site for $w h$-phrases in root (main) clauses, as noted earlier. So, consider in this light an utterance and some echo candidates such as those in (11) but with the split CP structure shown in (23). In these sentences, the focus layer contains a wh-phrase. Such sentences appear to indicate that perhaps the Focus layer is frozen in EQ formation; perhaps an EQ CP must retain the particular wh-phrase content and complementizer type of the FocusP of the utterance it is echoing.

(23) a. U: ...[FocP What [Foc ${ }^{\circ}$ did] ... [IP Jack the Ripper eat at the party]]?

b. E: ...[FocP What $\left[\mathrm{Foc}^{\circ} \mathrm{did}\right]$... [IP who eat at the party]]? 
c. *E: ...[FocP Who $\left[\mathrm{Foc}^{\circ} \varnothing\right]$... [IP ate what at the party $\left.]\right]$ ?

Thus, it appears here that we might claim that Comp freezing applies to the Focus layer in a split CP analysis.

However, this freezing result is not consistent when we consider Focus with other content. The sentences of (24) illustrate the echo questioning of utterances involving a non-interrogative focused argument which is also claimed to land in the Focus layer:

(24) a. U: HIS BOOK they should give to Mozart (not mine).

(cf. Rizzi’s (1997: 285, (2))

$\mathrm{a}^{\prime} \quad$...[FocP HIS BOOK [ $\left.\mathrm{Foc}^{\circ} \varnothing\right]$... [IP they should give to Mozart]]

b.??E: HIS BOOK they should give to who?

$\mathrm{b}^{\prime} \quad \ldots\left[\mathrm{FocP} \mathrm{HIS}\right.$ BOOK $\left[\mathrm{Foc}^{\circ} \varnothing\right] \ldots$ [IP they should give to who]]?

c. E: They should give his book to who?

$\mathrm{c}^{\prime} \quad$ [(Force)/FinP [(Force)/Fin ${ }^{\circ}$ Ø] [IP They should give his book to who $\left.]\right]$ ?

(Here, the examples with primes indicate the relevant split CP analysis of each sentence.) Clearly, $\left(23 \mathrm{c} / \mathrm{c}^{\prime}\right)$ is quite viable as a syntactic EQ to $\left(23 \mathrm{a} / \mathrm{a}^{\prime}\right)$, and in fact it seems preferable to $\left(23 \mathrm{~b} / \mathrm{b}^{\prime}\right)$, an EQ which sounds a bit strained. However, the CP structure of $\left(23 \mathrm{c} / \mathrm{c}^{\prime}\right)$ bears little resemblance to that of $\left(23 \mathrm{a} / \mathrm{a}^{\prime}\right)$. Thus, we have two problems. First, in apparent contradiction to the wh-phrase result in (23), the Focus layer in the EQs of (24) is not frozen. The best EQ has a distinct CP structure from its utterance. Second, the EQ which does contain a frozen CP isn't very good.

The first problem doesn't exist under the classic CP analysis, as shown in (25).
(25) a. U: [CP $\varnothing \quad$ [HIS BOOK [they should give to Mozart]] $[-\mathrm{WH}]$
b.??E: $\left[\mathrm{CP}_{\mathrm{i}} \mathrm{Q}_{\mathrm{CP}} \varnothing \quad\right.$ [HIS BOOK [they should give to $\left.\left.\left.\left.\mathrm{who}_{\mathrm{i}}\right]\right]\right]\right]$ ? $[-\mathrm{WH}]$
c. $\mathrm{E}:\left[\mathrm{CP}_{\mathrm{i}} \mathrm{Q}_{\mathrm{CP}} \quad \varnothing \quad\left[\right.\right.$ they should give his book to $\left.\left.\left.\mathrm{who}_{\mathrm{i}}\right]\right]\right]$ ? $[-\mathrm{WH}]$

In both of the EQs (25b) and (25c), Comp is frozen. Therefore, (25c) is predicted to be a good EQ to (25a). As for the problem of accounting for the oddity of (25b), focused phrases appear to behave in a manner more comparable to low elements like topics or like elements in passive constructions: in this analysis they are lower than, and are not a part of, a frozen CP. The somewhat unnatural character of (25b) may be accounted for in terms of a conflict of clause type. That is, perhaps a syntactic focus 
construction is a type of assertion that conflicts with interrogation. Moving the focused phrase out of pre-subject focus position resolves the conflict, and here, such repositioning is possible since focus phrases are not a part of the frozen CP layer. Thus, $(25 \mathrm{c})$ is a preferable EQ to (25b).

In more explicit structural terms, perhaps the syntactic signal for the focus clause type is the focus phrase appearing left-edge. EQ formation might corrupt such a signal, since in the EQ, the B-binder appears left-most. Movement of the phrase resolves the conflict.

A possible way to attempt to salvage the split $\mathrm{CP}$ analysis here relative to EQ formation might be to say that the echo questioning itself involves or introduces a type of focusing. We might then derive the inability to 'stack' EQ elements and non-interrogative Focus elements from Rizzi's proposed ban on recursive focusing. ${ }^{4}$ But this only muddies the waters. Clearly, multiple interrogative elements may occur, either in normal questions as in (26), or in EQs as in (27), at least at LF:

(26) Who ordered what?

(27) a. U: (Mary said that) Beethoven liked chocolate ants.

b. E: (Mary said that) Who liked what?

Hence, it is not clear that interrogative elements, which may indeed stack, are working at all like other non-interrogative Focus elements, which are claimed not to stack. Further, this approach may be mute since, as Newmeyer (2004) points out, multiple discontinuous focusing is possible in a single sentence, which would entail (covert) stacking of focus elements.

There is a further problem with what appears thus far to be the most reliably frozen layer within split CP in EQs, namely, the Focus layer with interrogative content. As noted earlier, it is only in main/root clauses that whphrases are said to land in the Focus layer. In embedded clauses, they are claimed to land in the Force layer. Nonetheless, embedded EQ clauses exhibit the same apparent freezing of CP elements as root clauses do, as illustrated in (28).

(28) a. U: They wondered what Mozart ate at Mary's party.

b. E: They wondered what who ate...?

c. ${ }^{*} \mathrm{E}$ : They wondered who ate what...?

d. *E: They wondered if who ate what...?

e. *E: Who did they wonder ate what...?

f. *E: Did they wonder what who ate...?

\footnotetext{
${ }^{4}$ See note 1 .
} 
In fact, the whole CP network appears (relative to the classic CP analysis) to be frozen. In (28), the root EQ CP must remain simple declarative, and the embedded CP must contain what, as in (28b). Thus, overall it appears that there is little correspondence between, on the one hand, the elements that appear frozen in EQs, and on the other, any consistent location or layers in split CP. In the end, Focus, like Force, Topic, and Finiteness, does not appear to consistently allow a 'freezing' account of possible EQs. Perhaps something else is at work, but it is not obvious what that might be.

\section{Final Observations on EQ Formation}

To summarize this part of the discussion, the Comp freezing of basic CP features in English EQs can be characterized rather neatly and straightforwardly in something like the classic CP analysis: the CP layer consists solely of Spec,CP and $\mathrm{C}$ is uniformly frozen, with the phonetic character of $\mathrm{C}$ not at issue. However, there appears to be a variety of complications in attempting to characterize English EQs within the split CP hypothesis. The picture of EQ formation, which is sharp in classic CP terms, loses resolution in split CP terms. Though a finding like this is by no means conclusive about the correctness or incorrectness of a given theory of $\mathrm{CP}$, it nonetheless points toward the possibility that English CP structure involves something more like the classic architecture than the split architecture suggested by Rizzi.

Perhaps in closing this topic of EQs, it is worth noting that there are other English CP facts for which the split CP hypothesis appears non-optimal. For instance, as the sentences in (29) illustrate and as has been widely noted, in English (as opposed to Italian), Topic elements are not compatible with moved wh-phrases:

(29) a. Who will you give your book to?

b. *Your book, who will you give to?

c. *Your book, who will give to me?

Further, Topics and AvPs show a parenthetical intonational pattern which is unexpected from the point of view of the split CP analysis.

Finally, if that is Force and if wh-phrases move to Spec,FocP, a position below Force, then we obtain the wrong order for interrogative constructions with a 'doubly-filled Comp' where they have been attested to appear in English. For example, in Middle English (ME), we find constructions such as (30b) (which should have main clause syntax) and (31a-b). In these sentences, the moved $w h$-phrase precedes rather than follows the complementizer:

(30) a. U: Madame, quod he, how thynke ye herby? 
b. E: How that me thynketh? quod she,...

(Chaucer 1387-1394: 99)

(31) a. U: '...3et wist I neuere wel what that he mente.'

b. E: 'What that I mene, O swete herte deere?'

(Chaucer 1385: 254)

In fact, these sentences are doubly interesting: the (b) examples appear to be EQs in ME. As we would predict, the classic CP elements, that is, the whphrase and the complementizer, are frozen, though other elements vary appropriately. In (30) we see a type of variation which is also available in Modern English: in instances where the complementizer that is optionally realized, the EQ may show it or not, as noted earlier. When the complementizer is phonetically realized, it appears to the right of, or below, the wh-phrase, whether root or embedded. This is the normal pattern: $w h$ phrase preceding complementizer.

\section{Negative Inversion and Echo Negation}

Now I would like to turn to negative inversion, and what appears to be another echo phenomenon, something that I will call 'echo negation'. The Negative Inversion (NI) construction is illustrated in (32a).

(32) a. U: Rarely does he order pizza with pineapple.

$\mathrm{a}^{\prime} \quad$...[FocP Rarely [ $\mathrm{Foc}^{\circ}$ does]...[IP he order pizza with pineapple ]]...

As shown in $\left(32 \mathrm{a}^{\prime}\right)$, this construction has been claimed to parallel the split CP analysis of questions (Haegeman 2000; Haegeman \& Guéron 1999). Here, the negative expression occupies Spec,FocP, as wh-phrases are claimed to do, and a verb moves to $\mathrm{Foc}^{\mathrm{o}}$, as it is also claimed to do in questions. Of further interest is the possibility of 'echo negation' (EN), as in (32b) and (32c).

(32) b. EN:Rarely DOESN'T he order pizza with pineapple!

c. EN: He rarely DOESN'T order pizza with pineapple!

When taking issue with the polarity of an utterance like (32a), it is possible to insert a second negative which would in other contexts be somewhat strangesounding, perhaps not unlike the insertion of an echo wh-phrase. Also in parallel with an EQ-inserted wh-phrase, the inserted negative is stressed. Thus, these features make ENs at least superficially similar to EQs. Following this line of thinking, if both questions and NI constructions shared the same CP positioning properties, we might expect ENs to also share the more significant abstract properties of EQs, strengthening the case for such a parallel analysis. So we turn to the question of whether echo negation shows the same CPrelated properties as EQs. 
One significant property of EQ formation is that a newly introduced whphrase takes wide scope (in the sense of having 'root' interrogative force) relative to any other $w h$-phrase already present in the utterance. This was noted earlier in the set (11a), (12c), and (13), repeated here.

(11) a. U: [CP What did [IP Jack the Ripper eat at the party]]?

(12) c. $E: Q_{j}\left[{ }_{C P} W_{h a t}\right.$ did $\left[{ }_{I P} W_{h o}\right.$ eat at the party $\left.\left.t_{i}\right]\right]$ ? (=11b)

(13) a. *R: Peanuts!

b. R: Jack the Ripper!

In $(12 \mathrm{c})$, it is only the B-bound $w h o_{j}$ that has 'root' interrogative force, as indicated by the fact that its only possible response is (13b).

Consider in this light the scope of an EN-introduced negative as in (32b).

(32) b. EN: Rarely DOESN'T he order pizza with pineapple!

If doesn't in (32b) took wide scope (something like an EQ-introduced whphrase), then sentence (32b) should mean 'It is not the case that he rarely orders pizza with pineapple'. That is, perhaps he never orders it, perhaps he sometimes orders it, or perhaps he always orders it. However, (32b) doesn't have such meanings. Rather, it means 'It is rare that he doesn't order pizza with pineapple'. That is, he nearly always orders it. Thus, a newly-introduced negative takes narrow scope relative to the already-present negative expression, behaving in this respect quite differently from an EQ-introduced wh-phrase.

A related second property is (as noted earlier) that an already-present whphrase loses 'root' interrogative force in an EQ, a fact again illustrated by the impossibility of response (13a) above to (12c). However, in the EN construction, the already-present negative rarely has in every respect the same semantic force in the EN construction that it does in the original NI construction: it means 'It is rare that $X$ ', where in (32a) $X$ is an affirmative proposition, and in (32b) $\mathrm{X}$ is a negative proposition.

Third, as was argued earlier at some length, a wh-phrase in the CP layer of an utterance is frozen in the CP layer of its EQ. However in the case of EN, the negative expression is not frozen in, as indicated by the fact that sentence (32c) (repeated here) is an equally possible EN to (32a).

(32) c. EN: He rarely DOESN'T order pizza with pineapple!

Thus, NI constructions and their ENs do not appear to behave in parallel to CP-related aspects of EQs, as might have been expected under a parallel split $\mathrm{CP}$ analysis. Again, this is not strong evidence against such an analysis, but much might have been made out of it if these facts had turned out differently. 


\section{Final Remarks}

Here, I have tried to consider facts about EQ formation and what they might indicate about the nature of the CP layer. The classic CP analysis appears to facilitate a straightforward characterization of what some of the major limitations are on forming an EQ to a particular utterance. In a nutshell, a central limitation may be stated as Comp-freezing, as spelled out above. When one reanalyzes the $\mathrm{CP}$ layer as split, any tight correspondence between the elements that are frozen and the structure of $\mathrm{CP}$ dissolves. No comparably easy statement of utterance-echo correspondences appears to be available. If one kind of evidence favoring one description over another is that one description facilitates capturing generalizations that the other does not, then the EQ evidence seems to favor the classic CP analysis over the split $\mathrm{CP}$ analysis, at least as far as these English data are concerned.

\section{References}

Chaucer, Geoffrey. 1385. Troilus and Criseyde. University of Virginia Middle English Text Archive, Charlottesville.

Chaucer, Geoffrey. 1387-1394. The Canterbury Tales. University of Virginia Middle English Text Archive, Charlottesville.

Chomsky, Noam. 1977. Essays on Form and Interpretation. North Holland, New York.

Chomsky, Noam. 1995. The Minimalist Program. MIT Press, Cambridge, MA.

Culicover, Peter W. 1992a. Polarity, Inversion, and Focus in English. ESCOL '91. Department of Linguistics, The Ohio State University, Columbus, pp. 46-68.

Culicover, Peter W. 1992b. Topicalization, Inversion, and Complementizers in English. In Denis Delfitto et al, eds., Going Romance and Beyond. University of Utrecht, Utrecht.

Dumitrescu, Domnita. 1990. The Grammar of Echo Questions in Spanish and Romanian. Ph.D. diss., University of Southern California, Los Angeles.

Dumitrescu, Domnita. 1991. Spanish Echo Questions and Their Relevance for Current Syntactic Theory. Southwest Journal of Linguistics 10: 42-565.

Haegeman, L. 2000. Inversion, Non-adjacent Inversion and Adjuncts in CP. In P. Rowlett, ed., Transactions of the Philological Society. Blackwell, Oxford, pp. 121-160.

Haegeman, L. \& J. Guéron. 1999. English Grammar. Blackwell, Oxford.

Lasnik, Howard \& Mamoru Saito. 1992. Move Alpha. MIT Press, Cambridge, MA.

Newmeyer, Frederick. 2004. On Split CPs, Uninterpretable Features, and the 'Perfectness' of Language. This volume.

Pesetsky, David. 1987. Wh- in Situ. In E. J. Reuland and A. G. B. ter Meulen, eds., The Representation of (In)Definiteness. MIT Press, Cambridge, MA, pp. 98-129.

Rizzi, Luigi. 1990. Relativized Minimality. MIT Press, Cambridge, MA.

Rizzi, Luigi. 1997. The Fine Structure of the Left Periphery. In, Liliane Haegeman, ed., Elements of Grammar. Kluwer, Dordrecht, pp. 281-337.

Sobin, Nicholas. 1978. On Echo Questions in English. In D. Lance and D. Gulstad eds., Papers from the 1977 Mid-America Linguistics Conference, University of Missouri, Columbia, pp. 247-259.

Sobin, Nicholas. 1990. On the Syntax of English Echo Questions. Lingua 81: 141-167.

Sobin, Nicholas. 2002. The Comp-Trace Effect, the Adverb Effect and Minimal CP. Journal of Linguistics 38:527-560. 